\title{
Correlação entre uso da terra e qualidade da água subterrânea
}

\author{
Correlation between land use and groundwater quality
}

\section{João Paulo Cunha de Menezes', Ana Paula Almeida Bertossi², Alexandre Rosa Santos ${ }^{3}$, Mirna Aparecida Neves ${ }^{4}$}

\begin{abstract}
RESUMO
Este trabalho descreve a correlação entre parâmetros de uso da terra (área agricultada, área edificada, pastagem, solo exposto e vegetação intermediária) e de qualidade da água subterrânea ( $\mathrm{pH}$, sólidos totais dissolvidos - STD, $\mathrm{K}^{+}, \mathrm{Na}^{+}, \mathrm{Fe}^{+3}, \mathrm{Ca}^{+2}, \mathrm{Mg}^{+2}, \mathrm{NO}_{2}, \mathrm{NO}_{3}$, P total e coliformes), no sul do estado do Espírito Santo. A delimitação da área de influência de poços e a identificação das classes de uso da terra foram feitas utilizandose Sistema de Informações Geográficas. Por meio da análise de correlação canônica, foi possível estimar dois índices: índice de uso da terra e índice de qualidade da água, ambos padronizados. A correlação canônica foi significativa entre o primeiro par de variáveis canônicas, indicando relação linear entre os grupos. Desta forma, é possível afirmar que o uso da terra influenciou a qualidade da água subterrânea, principalmente pelo incremento da concentração de alguns elementos químicos.
\end{abstract}

Palavras-chave: uso do solo; qualidade da água; água subterrânea.

\begin{abstract}
This work describes the correlation between the parameters of land use (cropped area, built area, pasture, exposed soil and intermediate vegetation) and groundwater quality $(\mathrm{pH}$, total dissolved solids - TDS, $\mathrm{K}^{+}, \mathrm{Na}^{+}, \mathrm{Fe}^{+3}, \mathrm{Ca}^{+2}, \mathrm{Mg}^{+2}, \mathrm{NO}_{2}, \mathrm{NO}_{3}$; total-P and coliforms) in southern of the Espírito Santo state, Brazil. The delimitation of areas that influence wells and the identification of land use classes were made using Geographical Information System. Through canonical correlation analysis, it was possible to estimate two indexes: land use index and water quality index, both standardized. The canonical correlation was significant between the first pair of canonical variables, indicating linear relationship between the groups. Thus, it was possible to confirm that land use influenced groundwater quality, mainly by the increase in the concentration of some chemical elements.
\end{abstract}

Keywords: land use; water quality; groundwater.

\section{INTRODUÇÃO}

A demanda por recursos hídricos tem se expandido com o aumento das atividades humanas em diversas regiões, resultando em preocupações ecológicas e ambientais. Em geral, a qualidade da água subterrânea pode ser influenciada por vários processos, dentre os quais destacam-se: processos naturais, como velocidade da água no aquífero, qualidade da recarga, interação com solos e rochas, interação com outros tipos de aquíferos etc. (HUNTINGTON, 2006) e atividades antropogênicas, incluindo agricultura, indústria e desenvolvimento urbano (JEONG, 2001; OKI; KANAE, 2006).

Vários autores têm relatado a contaminação da água subterrânea como consequência do uso da terra (CHAE et al., 2004; DAS et al.,
2010; MIRLEAN et al., 2005; CALIJURI et al., 2012; LI; MERCHANT, 2013; STROHSCHÖN et al., 2013; WHITE et al., 2013). Os impactos do uso da terra sobre a qualidade da água subterrânea incluem: aumento das concentrações de íons, mudanças nas condições de óxido-redução e aumento das concentrações de elementos secundários nas regiões em desenvolvimento em comparação com regiões não desenvolvidas (TROJAN et al., 2003). Cain et al. (1989) observaram que a frequência de deteção de compostos orgânicos voláteis e alguns oligoelementos foram maiores na água do solo em áreas urbanas ou industriais, em comparação com zonas subdesenvolvidas. A água do solo em áreas agrícolas apresentou concentrações de nitrato mais elevadas e aumento na frequência de detecção de pesticidas em

'Doutorando em Recursos Hídricos pela Universidade Federal de Lavras (UFLA) - Lavras (MG), Brasil.

Engenheira Agrônoma e Mestre em Ciências Florestais pelo Centro de Ciências Agrárias da Universidade Federal do Espírito Santo (UFES) - Alegre (ES), Brasil. ${ }^{3}$ Doutor em Engenharia Agrícola pela Universidade Federal de Viçosa (UFV). Professor e pesquisador do Centro de Ciências Agrárias da UFES - Alegre (ES), Brasil. ${ }^{4}$ Doutora em Geologia pela Universidade Estadual Paulista "Júlio de Mesquita Filho" (UNESP). Professora e pesquisadora do Centro de Ciências Agrárias da UFES - Alegre (ES), Brasil. Endereço para correspondência: João Paulo Cunha de Menezes - Centro de Ciências Agrárias da Universidade Federal do Espírito Santo - Alto Universitário, s/n - Guararema 29500-O00 - Alegre (ES), Brasil - E-mail: jpaulo_bio@hotmail.com

Recebido: 23/02/12 - Aceito: 21/11/13 - Reg. ABES: 238 
comparação com áreas subdesenvolvidas. Os autores relatam que os efeitos das atividades humanas sobre a qualidade da água aumentam à medida que a urbanização ou a irrigação se intesificam.

Essa influência pode ser avaliada de diversas formas, como, por exemplo, usando-se um raio fixo em torno do poço (NOLAN et al., 2002; SQUILLACE et al., 2002). Nos trabalhos feitos por Nolan et al. (2002) e Squillace et al. (2002), a degradação da qualidade da água subterrânea foi classificada e avaliada utilizando-se um círculo com raio de $500 \mathrm{~m}$, centrado no poço. Em outros estudos, o uso da terra foi estudado dentro de raios variando de 100 a $3.200 \mathrm{~m}$ (AN et al., 2005; BRUCE; McMAHON, 1996; TROJAN et al., 2003).

Devido à grande quantidade de variáveis que compõem os parâmetros de qualidade da água e do uso da terra, a interpretação desses resultados torna-se difícil e dispendiosa (SHRESTHA; KAZAMA, 2007). Deste modo, os métodos de análise multivariada de dados têm sido cada vez mais utilizados em estudos ambientais devido à sua fácil aplicação e por reduzirem o número de dados em subgrupos menores correlacionados entre si, além de identificarem as variáveis que são responsáveis pela dispersão das observações
(HAIR, 1998). Aliada aos Sistemas de Informações Geográficas (SIGs) e ao Sensoriamento Remoto, a análise multivariada representa importante ferramenta para os estudos de problemas de qualidade de água, fornecendo apoio a projetos de planejamento e manejo dos recursos hídricos.

Assim, o objetivo deste trabalho consistiu em descrever a correlação entre os parâmetros de uso da terra e a qualidade da água subterrânea em um município típico do interior capixaba. A pesquisa poderá contribuir para traçar estratégias de planejamento e gerenciamento integrado dos espaços rurais no que se refere à melhoria e manutenção da qualidade dos recursos naturais.

\section{MATERIAL E MÉTODOS}

A área de estudo corresponde ao município de Alegre, que abrange $773 \mathrm{~km}^{2}$ no extremo sul do estado do Espírito Santo (Figura 1).

Segundo a classificação internacional de Köppen, o clima da região é do tipo "Cwa", isto é, tropical quente e úmido, com inverno frio e seco e verão chuvoso. A temperatura anual média é de $23,1^{\circ} \mathrm{C}$

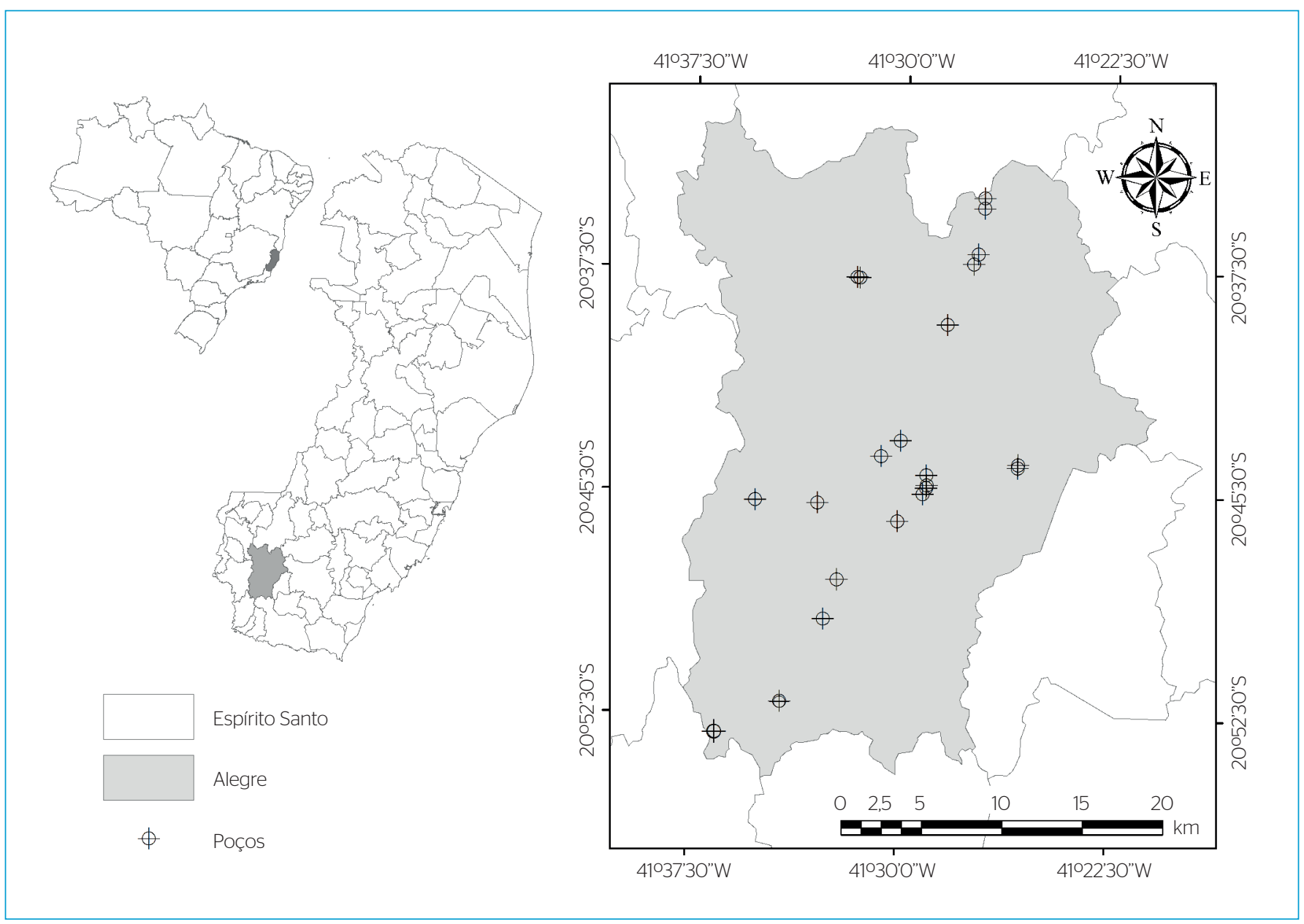

Figura 1 - Área de estudo e localização dos pontos de coleta no munício de Alegre, Espírito Santo, Brasil. 
e a precipitação total anual média, de $1.341 \mathrm{~mm}$. De maneira geral, a topografia da região possui relevo bastante acidentado intercalado por reduzidas áreas planas (IBGE, 2010). A atividade econômica mais importante da região é a agropecuária, tendo como destaque o café Conilon (Coffea canephora Pierre ex Froehner) e a pecuária, com um rebanho bovino de aproximadamente 64.160 cabeças (IBGE, 2010).

O sistema aquífero cristalino é o manancial de água subterrânea existente na área, sendo composto por uma camada porosa chamada manto de intemperismo (ou rocha alterada) e, abaixo desta, a rocha cristalina fraturada (LACHASSAGNE et al., 2001). Em grande parte do Sudeste brasileiro, o aquífero presente na rocha cristalina, conhecido como aquífero fraturado ou fissural, é composto por granitos e gnaisses que podem fornecer água apenas em locais onde o fraturamento da rocha permite a percolação da água (NEVES; MORALES, 2006). Já a água presente no manto de intemperismo ocupa os espaços entre grãos e tem grande importância nos países em desenvolvimento, pois, para abastecimento doméstico e irrigação em pequena escala, as pequenas vazões ali encontradas são suficientes e, muitas vezes, constitui a única opção de abastecimento (CHILTON; FOSTER, 1995). Sua explotação é rasa, obtida com tecnologia simples e de baixo custo, fatores importantes quando a água superficial normalmente é insuficiente em termos de qualidade e quantidade.

\section{Coleta e análise da água}

Foram coletadas amostras em 20 poços de abastecimento (Figura 1) para análise física, química e microbiológica no mês de fevereiro de 2011. A coleta de água seguiu as recomendações da NBR 9898 e do Standard Methods for the Examination of Water and Wastewater (ABNT, 1987; APHA; AWWA; WEF, 2005). Antes de cada coleta, foi feito um bombeamento de cerca de 30 minutos em cada poço. Os frascos de coleta foram lavados com a água do ponto de coleta e, para a análise microbiológica, foram utilizados frascos devidamente esterilizados. As amostras foram rotuladas e refrigeradas a $4^{\circ} \mathrm{C}$, até serem levadas ao laboratório.

É importante citar que o estudo retratou a situação de qualidade da água durante o verão, que corresponde ao período das chuvas nessa região do Brasil. Nessa época, espera-se que a recarga do aquífero seja mais acelerada a partir das águas de infiltração, favorecendo a entrada de elementos a partir da superfície do terreno.

Como a área estudada possui uso predominantemente agrícola e com criação de pecuária de forma extensiva, optou-se por analisar 11 parâmetros de qualidade da água, considerados relevantes para um direcionamento da questão da qualidade da água. São eles: sólidos totais dissolvidos (STD), potencial hidrogeniônico $(\mathrm{pH})$, cátions $\left(\mathrm{Fe}^{+3}, \mathrm{Ca}^{+2}\right.$, $\mathrm{K}^{+}, \mathrm{Mg}^{+2}, \mathrm{Na}^{+}$), ânions $\left(\mathrm{NO}_{2}{ }^{-}, \mathrm{NO}_{3}^{-}\right)$, P total e coliformes termotolerantes. Utilizaram-se os métodos da APHA, AWWA e WEF (2005), com exceção do pH e do STD. Para análise do pH, foi utilizado um medidor portátil de campo, e os sólidos totais dissolvidos foram determinados pelo método gravimétrico de acordo com a NBR 10664 (ABNT, 1989). Para cada ponto, realizaram-se três repetições das medidas a fim de conduzir a uma maior confiabilidade dos resultados obtidos; apenas para o parâmetro coliformes, foi realizada somente uma observação. Em seguida, foi calculada a média dos parâmetros de qualidade da água para serem utilizados na modelagem estatística. No cálculo do valor médio de $\mathrm{pH}$, primeiro converteu-se o valor do $\mathrm{pH}$ para seu valor em concentração de $\mathrm{H}^{+}\left(\left[\mathrm{H}^{+}\right]=10^{-\mathrm{pH}}\right)$ e calculou-se a média de $\mathrm{H}^{+}$, que é novamente convertido para o valor em unidades de $\mathrm{pH}(\mathrm{pH}=-\log$ $\left.\left[\mathrm{H}^{+}\right]\right)$. O uso da água para consumo humano exige a total ausência de coliformes termotolerantes; porém, já na primeira etapa de coleta, foi constatada a presença desses micro-organismos em todas as amostras, considerando-se, portanto, desnecessário realizar mais campanhas de coleta, visto que o primeiro resultado já foi positivo.

\section{Delimitação das áreas de influência para geração dos mapas de uso da terra por intermédio das ferramentas de Sistemas de Informações Geográficas}

\section{Delimitação da área de influência dos poços}

A partir da base cartográfica vetorial fornecida pelo GEOBASES e pelo Ortofotomosaico em escala 1:15.000 cedido pelo Instituto Estadual de Meio Ambiente (IEMA), foram determinadas as 8 variáveis espaciais do uso da terra com o auxílio das ferramentas do SIGs $\operatorname{Arcgis}{ }^{\circledR} 10.0$ (ESRI, 2011). As etapas de geração das variáveis espaciais foram divididas em dois procedimentos básicos: a primeira foi a delimitação de um buffer em torno de cada ponto amostral, a partir dos pontos predefinidos para a coleta de água subterrânea. A segunda etapa foi a confecção dos mapas de uso da terra, utilizando-se as ortofotos disponibilizadas pelo IEMA (Anexo 1).

\section{Delimitação do buffer da área de proteção do poço}

Segundo Lobo-Ferreira et al. (2003, p. 2), define-se perímetro de proteção de poços (PPP) como:

a área de superfície e subsuperfície envolvente de uma ou mais captações destinadas ao abastecimento, onde atividades susceptíveis de alterar a qualidade da água subterrânea são limitadas, proibidas ou regulamentadas de modo progressivo.

Existem vários métodos para a delimitação de PPPs, sendo que todos trazem vantagens e desvantagens (HIRATA \& REBOUÇAS, 1999). Para a presente pesquisa, utilizou-se o método do raio fixo arbitrário, devido ao fato de ser um método simples, rápido e de baixo custo. Tal 
método baseia-se na definição de uma área circular, centrada no ponto de captação, com raio escolhido pelo pesquisador a partir da observação em campo e em imagem aérea.

Adotou-se um raio de $200 \mathrm{~m}$, segundo a metodologia do Raio Fixo Arbitrário (HIRATA \& REBOUÇAS, 1999). A dimensão do raio também levou em consideração trabalhos desenvolvidos em outras regiões (AN et al., 2005; BRUCE \& McMAHON, 1996; NOLAN et al., 2002; SQUILLACE et al., 2002; TROJAN et al., 2003). Embora a utilização de um raio de influência arbitrário possa parecer simplista por não levar em conta as variáveis hidrodinâmicas do aquífero, considera-se possível sua utilização em escala de detalhe e, principalmente, porque os poços estudados situam-se em áreas baixas (onde o lençol freático é menos profundo) que são cincundadas pelas vententes que constituem as áreas de recarga.

Para a delimitação dos buffers, foram usados os shapefiles (shp) dos pontos correspondentes aos poços, cujas coordenadas foram medidas em campo com o auxílio de GPS.

\section{Geração dos mapas de uso da terra}

As classes de uso da terra foram obtidas a partir da interpretação visual por meio de técnicas de fotointerpretação das ortofotos, visualizações com as imagens do GeoEye do aplicativo Google Earth e também por intermédio da inspeção de campo. As classes definidas foram: área agrícola, área edificada, corpos d'água, estrada pavimentada, fragmentos rochosos, pastagem, solo exposto e vegetação intermediária. Assim como para a definição dos buffers, o aplicativo computacional empregado foi o $\operatorname{ArcGis}^{\circledR}$ 10.0, que também foi utilizado para a geração dos mapas de uso da terra (Apêndice 1). Criou-se um shapefile do tipo polígono, digitalizado em tela em uma escala de 1:3.000.
Concomitantemente, as classes de uso da terra dentro da área de influência dos poços foram inseridas no banco de dados do $\operatorname{ArcGis}^{\circledR} 10$.

\section{Modelagem estatística}

Utilizou-se a técnica estatística multivariada "Análise de Correlação Canônica" (TIMM, 2002). Para tanto, foi definida uma amostra aleatória de 20 pares de vetores aleatórios $\tilde{X}$ e $\tilde{Y}$. O vetor $\tilde{X}$ é um vetor aleatório no qual os componentes correspondem às porcentagens da classe de uso da terra que possuem as maiores interferências antrópicas na área de estudo. Das oito variáveis levantadas relativas ao uso da terra, apenas cinco foram utilizadas por serem mais representativas na pesquisa, sendo que as demais pouco influenciaram os resultados (Quadro 1). As componentes do vetor $\tilde{X}$ foram obtidas da seguinte maneira: [(área de cada tipo de uso da terra da sub-bacia)/(área do shape da delimitação do buffer)], gerando valores adimensionais.

A definição dos componentes do vetor aleatório $\tilde{Y}$ está associada aos parâmetros de qualidade da água subterrânea (Quadro 2).

Após definidos os vetores aleatórios $\tilde{X}$ e $\tilde{Y}$, realizou-se uma análise exploratória dos dados. A média de cada uma das variáveis dos componentes foi comparada, com o objetivo de identificar variáveis assimétricas ou valores discrepantes. Ao comparar as médias das variáveis entre si, também foi possível verificar discrepâncias entre as escalas. Em seguida, foram obtidos os autovalores e autovetores normalizados

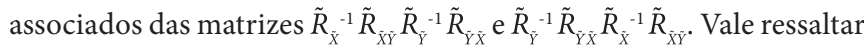
que os pares de variáveis canônicas apresentam variância igual a $1 \mathrm{e}$ que a correlação entre as variáveis $\mathrm{V}_{1}$ e $\mathrm{U}_{1}$ é máxima dentre todas as possíveis combinações lineares de $\tilde{X}^{\star}$ com as combinações lineares de $\tilde{Y}^{\star}$. O programa estatístico usado para análise dos dados (correlação de Pearson e correlação Canônica) foi o R-cran, versão 2.14.0.

Quadro 1 - Tipos de uso do solo utilizados na modelagem estatística.

\begin{tabular}{|c|c|c|}
\hline Vetor $\tilde{x}$ & Classes (percentagem) & Característica predominante \\
\hline$X_{1}$ & Área agricultada & Consideradas áreas de plantio de várias culturas \\
\hline$x_{2}$ & Área edificada & Formação não arbórea \\
\hline$x_{3}$ & Pastagem & Solos descobertos e sem a presença de área verde ou construções em padrãos urbano e também em áreas rurais \\
\hline$x_{4}$ & Solo exposto & Consideradas as áreas com vegetação arbórea intensa \\
\hline$x_{5}$ & Vegetação intermediária \\
\hline
\end{tabular}

Quadro 2 - Parâmetros de qualidade da água subterrânea utilizados na modelagem estatística.

\begin{tabular}{|c|c|c|c|c|c|c|c|c|c|c|c|}
\hline Vetor $\tilde{Y}$ & $Y_{1}$ & $Y_{2}$ & $Y_{3}$ & $Y_{4}$ & $Y_{5}$ & $Y_{6}$ & $Y_{7}$ & $Y_{8}$ & $Y_{9}$ & $Y_{10}$ & $Y_{11}$ \\
\hline Parâmetros & STD & $\mathrm{pH}$ & $\mathrm{K}^{+}$ & $\mathrm{Na}^{+}$ & $\mathrm{Fe}^{+3}$ & $\mathrm{Ca}^{+2}$ & $\mathrm{Mg}^{+2}$ & $\mathrm{NO}_{2}$ & $\mathrm{NO}_{3}$ & P total & Coliformes \\
\hline
\end{tabular}

STD: sólidos totais dissolvidos. 


\section{RESULTADOS E DISCUSSÃO}

\section{Análises exploratórias dos dados}

As médias dos vetores $\tilde{X}$ e $\tilde{Y}$, respectivamente, foram calculadas e organizadas para realização da modelagem estatística (Tabelas 1 e2). Existem grandes diferenças entre as médias das variáveis componentes de $\tilde{X}$ e $\tilde{Y}$ os valores do componente, indicando diferenças discrepantes de escala. Desta forma, optou-se por utilizar as matrizes de correlações amostrais $\tilde{R}_{X} \tilde{R}_{Y} \tilde{R}_{X Y}$ em lugar das matrizes de variâncias e covariâncias amostrais $\tilde{S}_{X} \tilde{S}_{Y} \tilde{S}_{X Y^{*}}$.

\section{Resultados das matrizes de correlação}

O coeficiente de correlação é utilizado para verificar relações entre variáveis independentes com variáveis dependentes (NAIR et al., 2005). A importância linear das variáveis na correlação é determinada pelos intervalos dos coeficientes $(-1,1)$. O coeficiente positivo sugere que as variáveis variam juntas no mesmo sentido, enquanto o coeficiente negativo indica que elas variam em sentido contrário. Cabe citar que, quando duas variáveis são estatisticamente independentes, o coeficiente de correlação linear é igual a zero $(\mathrm{p}=0)$. Entretanto, a recíproca não é verdadeira, ou seja, se o coeficiente de correlação linear for igual a zero $(\mathrm{p}=0)$, não significa que as variáveis sejam independentes. Isso ocorre porque o coeficiente de correlação linear, p, é uma medida da dependência linear entre as variáveis e, em algumas situações, podem apresentar dependência funcional não linear (TIMM, 2002). As Tabelas 3 e 4 apresentam os resultados das matrizes de correlação do vetor $\tilde{Y}$ e do vetor $\tilde{X} \operatorname{com} \tilde{Y}$, respectivamente.

Adotando significância de 5\%, existe correlação significativa e positiva entre os parâmetros STD, $\mathrm{Na}^{+}$e $\mathrm{Ca}^{+2} ; \mathrm{Ca}^{+2}$ e pH; e entre $\mathrm{P}$ total e $\mathrm{Fe}^{+3}$. $\mathrm{O} \mathrm{Na}$ foi o cátion de maior influência na concentração dos STD das águas estudadas $(\mathrm{r}=0,61 ; \mathrm{p}<0,05) . \mathrm{O} \mathrm{Ca}^{+2}$ foi o segundo cátion responsável pela concentração dos STD $(r=0,46$; $\mathrm{p}<0,05)$, apresentando também correlação significativa com o $\mathrm{pH}$ $(\mathrm{r}=0,48 ; \mathrm{p}<0,05)$. Deduz-se, portanto, que para a maioria das águas subterrâneas amostradas, esses parâmetros são originários de uma fonte comum. Isso implica que os elementos compartilham um mecanismo de liberação similar, que pode estar relacionado ao

Tabela 1 - Dados do vetor $\tilde{X}$ (parâmetros de uso da terra) para realização da modelagem estatística (Anexo 1).

\begin{tabular}{|c|c|c|c|c|c|}
\hline Poço & Área agricultada & Área edificada & Pastagem & Solo exposto & Vegetação intermediária \\
\hline 2 & 13,6495 & 13,4584 & 48,6406 & 5,9728 & 14,4376 \\
\hline 3 & 16,6191 & 14,2777 & 40,1325 & 6,3239 & 18,7956 \\
\hline 4 & 0,0000 & 0,7334 & 92,8515 & 2,6433 & 1,9545 \\
\hline 6 & 0,0000 & 6,1322 & 87,6629 & 0,0000 & 0,0000 \\
\hline 7 & 0,7719 & 2,9127 & 71,6971 & 5,4922 & 14,3968 \\
\hline 8 & 4,9224 & 3,0039 & 71,0403 & 10,2290 & 7,4402 \\
\hline 12 & 0,0000 & 0,6429 & 89,7812 & 1,5642 & 0,0000 \\
\hline 13 & 22,8966 & 0,7157 & 69,8402 & 0,6439 & 0,0000 \\
\hline 14 & 5,3096 & 0,4265 & 86,4403 & 2,5272 & 0,0000 \\
\hline 15 & 7,5371 & 0,5656 & 78,2157 & 10,4118 & 0,0000 \\
\hline 16 & 21,2467 & 0,2928 & 73,7806 & 0,6902 & 0,0000 \\
\hline 17 & 0,0000 & 0,6562 & 94,0358 & 4,3074 & 0,8421 \\
\hline 18 & 23,7576 & 1,5187 & 66,3992 & 5,2907 & 0,0000 \\
\hline
\end{tabular}

Nota: os valores correspondentes à área das classes de solo estão expressos em porcentagem. 
Tabela 2 - Dados do vetor $\tilde{Y}$ (parâmetros de qualidade da água) para realização da modelagem estatística.

\begin{tabular}{|c|c|c|c|c|c|c|c|c|c|c|c|}
\hline Poço & STD & $\mathrm{pH}$ & $\mathrm{K}^{+}$ & $\mathrm{Na}^{+}$ & $\mathrm{Fe}^{+3}$ & $\mathrm{Ca}^{+2}$ & $\mathrm{Mg}^{+2}$ & $\mathrm{NO}_{2}^{-}$ & $\mathrm{NO}_{3}$ & P total & Coliformes \\
\hline 2 & 54,47 & 6,03 & 7,77 & 5,83 & 0,00 & 0,09 & 1,03 & 0,01 & 0,17 & 0,16 & 120,0 \\
\hline 3 & 121,67 & 5,90 & 2,97 & 2,37 & 0,00 & 0,16 & 0,37 & 0,12 & 0,23 & 0,04 & 75,00 \\
\hline 4 & 69,27 & 6,47 & $1, \mathrm{OO}$ & 15,70 & 0,00 & 0,27 & 0,50 & 0,01 & 0,13 & 0,14 & 9,00 \\
\hline 6 & 49,30 & 5,47 & 2,97 & 11,33 & 0,00 & 0,00 & 0,39 & 0,06 & 0,05 & 0,15 & 4,00 \\
\hline 7 & 154,80 & 6,10 & 35,23 & 17,23 & 0,00 & 0,16 & 2,27 & 0,00 & 0,01 & 0,03 & 11,00 \\
\hline 8 & 109,33 & 6,50 & 5,27 & 16,40 & 0,33 & 0,29 & 1,03 & 0,00 & 0,32 & 0,35 & 4,00 \\
\hline 12 & 28,07 & 6,13 & 1,93 & 5,60 & 0,00 & 0,02 & 1,21 & 0,00 & 0,34 & 0,01 & 210,0 \\
\hline 13 & 68,19 & 6,43 & 4,13 & 18,63 & 0,00 & 0,46 & 0,40 & 0,01 & 0,23 & 0,23 & 11,00 \\
\hline 14 & 183,00 & 6,17 & 4,00 & 26,40 & 0,00 & 0,25 & 1,79 & 0,01 & 0,63 & 0,07 & 4,00 \\
\hline 15 & 2,63 & 6,20 & 2,07 & 7,63 & 0,00 & 0,06 & 0,99 & 0,01 & 0,53 & 0,01 & 9,00 \\
\hline 16 & 99,63 & 6,53 & 0,57 & 15,83 & 0,00 & 0,10 & 0,44 & 0,01 & 0,66 & 0,12 & 15,00 \\
\hline 17 & 107,27 & 6,40 & 1,50 & 14,03 & 0,00 & 0,40 & 0,75 & 0,01 & 0,18 & 0,16 & 15,00 \\
\hline 18 & 57,97 & 6,73 & 2,73 & 8,83 & 0,00 & 0,06 & 0,44 & 0,01 & 0,54 & 0,07 & 9,00 \\
\hline
\end{tabular}

Nota: os valores correspondentes às médias das variáveis sólidos totais dissolvidos (STD), $\mathrm{K}^{+}, \mathrm{Na}^{+}, \mathrm{Fe}^{+3}, \mathrm{Ca}^{+2}, \mathrm{Mg}^{+2}, \mathrm{NO}_{2}$; $\mathrm{NO}_{3}$ e P total apresentadas na tabela para modelagem dos dados estão em mg.L'1; para os coliformes termotolerantes, a unidade apresentada é NMP/100 mL (número mais provável em 100 mL).

Tabela 3 - Resultado da matriz de correlação do vetor $\check{Y}$, correspondente aos parâmetros de qualidade da água.

\begin{tabular}{|c|c|c|c|c|c|c|c|c|c|c|c|}
\hline & STD & $\mathrm{pH}$ & $\mathrm{K}^{+}$ & $\mathrm{Na}^{+}$ & $\mathrm{Fe}^{+3}$ & $\mathrm{Ca}^{+2}$ & $\mathrm{Mg}^{+2}$ & $\mathrm{NO}_{2}$ & $\mathrm{NO}_{3}^{-}$ & P total & Coliformes \\
\hline STD & 1,00 & - & - & - & - & - & - & - & - & - & - \\
\hline $\mathrm{pH}$ & 0,31 & 1,00 & - & - & - & - & - & - & - & - & - \\
\hline $\mathrm{K}^{+}$ & 0,35 & $-0,07$ & 1,00 & - & - & - & - & - & - & - & - \\
\hline $\mathrm{Na}^{+}$ & $0,61^{*}$ & 0,42 & 0,18 & 1,00 & - & - & - & - & - & - & - \\
\hline $\mathrm{Fe}^{+3}$ & 0,15 & 0,21 & 0,02 & 0,18 & 1,00 & - & - & - & - & - & - \\
\hline $\mathrm{Ca}^{+2}$ & $0,46^{*}$ & $0,48^{*}$ & $-0,02$ & 0,38 & 0,20 & 1,00 & - & - & - & - & - \\
\hline $\mathrm{Mg}^{+2}$ & 0,37 & 0,19 & 0,44 & 0,37 & 0,04 & 0,04 & 1,00 & - & - & - & - \\
\hline $\mathrm{NO}_{2}$ & 0,06 & $-0,32$ & $-0,13$ & $-0,33$ & $-0,11$ & $-0,11$ & $-0,24$ & 1,00 & - & - & - \\
\hline $\mathrm{NO}_{3}$ & $-0,02$ & $-0,04$ & $-0,35$ & $-0,21$ & 0,00 & $-0,05$ & $-0,32$ & $-0,18$ & 1,00 & - & - \\
\hline P total & 0,11 & 0,09 & $-0,11$ & 0,35 & $0,60^{*}$ & 0,27 & $-0,22$ & $-0,17$ & $-0,21$ & 1,00 & - \\
\hline Coliformes & 0,05 & $-0,07$ & $-0,11$ & $-0,44$ & $-0,13$ & 0,02 & $-0,12$ & $-0,02$ & 0,27 & $-0,21$ & 1,00 \\
\hline
\end{tabular}

*Correlação de Pearson significativa, $p<0,05$.

STD: sólidos totais dissolvidos. 
intemperismo das rochas. O manto de intemperismo que armazena essas águas é originário da alteração de rochas cristalinas, que são constituídas principalmente por óxidos de silício, alumínio, ferro, cálcio, sódio, magnésio e potássio. O intemperismo dos minerais que contêm silício, alumínio e ferro dá lugar aos materiais residuais insolúveis que permanecem in situ no perfil de alteração, enquanto a lixiviação dos minerais com cálcio, magnésio, potássio e sódio libera cátions que são transportados pela água (CUSTODIO \& LLAMAS, 1996). Esse processo parece estar contribuindo tanto para a salinidade quanto para a acidez da água na área estudada.

A concentração de $\mathrm{P}$ total nas águas, apesar de ter um índice de correlação relevante com o $\mathrm{Fe}^{+3}(\mathrm{r}=0,60 ; \mathrm{p}<0,05)$, não apresenta relação com a geologia, devido à escassez desse elemento nas rochas ígneas e metamórficas, o que requer outras fontes. Dentre as fontes mais prováveis, podem ser citados os aportes antropogênicos e a degradação da matéria orgânica (BHATTACHARYA et al., 2006; McARTHUR et al., 2001, 2004). O aporte antropogênico reside, fundamentalmente, nos efluentes domésticos, fossas sépticas, currais e na aplicação de fertilizantes. A contribuição, bem como a identificação, das atividades antrópicas para o P na água subterrânea é de difícil mensuração, pois não se registra correlação desse ânion com traçadores de contaminação.

Desta forma, a correlação significativa entre o $\mathrm{Fe}^{+3}$ e o P total pode indicar uma possível alteração da qualidade da água por matéria orgânica lixiviada, provinda de dejeto animal. A liberação de P na água subterrânea decorre da ação microbiana na dissolução redutiva do $\mathrm{Fe}^{+3}$ ligado ao $\mathrm{P}$. Em condições anaeróbicas, o $\mathrm{Fe}^{+3}$ é reduzido a $\mathrm{Fe}^{+2}$ e, com isso, tem-se a liberação do $\mathrm{P}$ presente na matéria orgânica (BHATTACHARYA et al., 2006; McARTHUR et al., 2001, 2004).

Conforme observado na Tabela 4, há correlações positivas e negativas entre as porcentagens dos usos da terra e os parâmetros de qualidade da água. A porcentagem de área agricultada apresentou correlação negativa com o $\mathrm{Na}^{+}(\mathrm{r}=-0,45 ; \mathrm{p}<0,05)$ e $\mathrm{Mg}^{+2}(\mathrm{r}=-0,47 ; \mathrm{p}<0,05)$; essas duas relações podem ser consideradas espúrias, havendo possivelmente variáveis de confundimento. A área agricultada apresentou correlação positiva com $\mathrm{NO}_{3}{ }^{-}(\mathrm{r}=0,61 ; \mathrm{p}<0,05)$. Para as porcentagens de área edificada, observa-se correlação positiva com o $\mathrm{NO}_{2}^{-}(\mathrm{r}=0,69$; $\mathrm{p}<0,05)$ e, para a classe de vegetação intermediária, correlação positiva com os íons de $\mathrm{K}^{+}(\mathrm{r}=0,51 ; \mathrm{p}<0,05)$ e de $\mathrm{NO}_{2}^{-}(\mathrm{r}=0,48 ; \mathrm{p}<0,05)$, lembrando que a ordem das variáveis não altera as correlações.

\section{Variáveis canônicas}

Na Tabela 5, apresentam-se os valores dos pares canônicos entre as classes de uso da terra (Grupo I) e os parâmetros de qualidade da água (Grupo II).

O número de funções canônicas gerado neste trabalho é o mínimo entre $(\mathrm{p}=5 ; \mathrm{q}=11)=5$, onde $\mathrm{p}$ é o número de variáveis do Grupo I e q é o número de variáveis que formam o Grupo II. Porém, esses valores são realizações aleatórias de uma amostra; logo, é necessário testar quantos autovalores são significativamente diferentes de zero. Entretanto, em uma amostra de tamanho n=20, é impossível realizar qualquer teste estatístico paramétrico, pois estes exigem grandes amostras. Desta forma, a significância da hipótese de nulidade em que todas as possíveis correlações canônicas são nulas foi avaliada utilizando-se o teste do $\chi^{2}$. Somente o primeiro par das variáveis canônicas $\left(\mathrm{V}_{1}, \mathrm{U}_{1}\right)$ foi considerado na presente pesquisa, por ser o único significativo ao nível de $5 \%$ de probabilidade de erro. O primeiro par de variáveis canônicas $\left(\mathrm{V}_{1}, \mathrm{U}_{1}\right)$ é formado da seguinte maneira:

$$
\begin{aligned}
V_{1}=\breve{\alpha}_{1} \breve{\mathbf{X}}^{*}= & 1,5444 \mathbf{X}_{1}^{*}+0,0039 \mathbf{X}_{2}^{*}+1,192 \mathbf{X}_{3}^{*}+0,4061 \mathbf{X}_{4}^{*}+0,8144 \mathbf{X}_{5}^{*} \\
U_{1}=\breve{\beta}_{1} \breve{\mathbf{X}}^{*}= & -0,0674 \mathbf{Y}_{1}^{*}+0,3221 \mathbf{Y}_{2}^{*}+0,6661 \mathbf{Y}_{3}^{*}-0,7362 \mathbf{Y}_{4}^{*}-0,3293 \mathbf{Y}_{5}^{*}+0,3085 \mathbf{Y}_{6}^{*} \\
& -0,1542 \mathbf{Y}_{7}^{*}+0,1829 \mathbf{Y}_{8}^{*}+0,8874 \mathbf{Y}_{9}^{*}+0,5748 \mathbf{Y}_{10}^{*}-0,2649 \mathbf{Y}_{11}^{*}
\end{aligned}
$$

onde:

$\widetilde{\alpha}_{1}^{\prime}$ : primeira coluna da Tabela 5 do Grupo I;

Tabela 4 - Resultado da matriz de correlação do vetor $\tilde{X}$ com o vetor $\tilde{Y}$, correspondente às classes de uso da terra com os parâmetros da qualidade da água.

\begin{tabular}{l|c|c|c|c|c|c|c|c|c|c|c} 
& $\mathrm{STD}$ & $\mathrm{pH}$ & $\mathrm{K}^{+}$ & $\mathrm{Na}^{+}$ & $\mathrm{Fe}^{+3}$ & $\mathrm{Ca}^{+2}$ & $\mathbf{M g}^{+2}$ & $\mathrm{NO}_{2}$ & $\mathrm{NO}_{3}$ & $\mathrm{P}_{\text {total }}$ & $\mathbf{C o l i f o r m e s}$ \\
\hline Área agricultada & $-0,17$ & $-0,08$ & $-0,16$ & $-0,45^{*}$ & $-0,13$ & 0,05 & $-0,47^{*}$ & 0,05 & $0,61^{*}$ & 0,03 & 0,19 \\
\hline Área edificada & 0,07 & $-0,31$ & 0,13 & $-0,37$ & 0,02 & $-0,18$ & $-0,09$ & $0,69^{*}$ & $-0,30$ & 0,07 & 0,19 \\
\hline Pastagem & $-0,03$ & 0,20 & $-0,16$ & 0,38 & $-0,03$ & 0,17 & 0,10 & $-0,35$ & $-0,01$ & $-0,19$ & $-0,14$ \\
\hline Solo exposto & $-0,12$ & $-0,12$ & 0,19 & $-0,24$ & 0,33 & $-0,23$ & $-0,02$ & $-0,09$ & 0,05 & 0,33 & $-0,10$ \\
\hline Vegetação intermediária & 0,31 & $-0,12$ & $0,51^{*}$ & $-0,13$ & 0,15 & $-0,03$ & 0,13 & $0,48^{*}$ & $-0,44$ & 0,08 & 0,07 \\
\hline
\end{tabular}

*correlação de Pearson significativa, $\mathrm{p}<0,05$.

STD: sólidos totais dissolvidos. 
Tabela 5 - Correlação canônica e pares canônicos entre as classes de uso da terra (Grupo I-V) e os parâmetros de qualidade da água subterrânea (Grupo II-U).

\begin{tabular}{|c|c|c|c|c|c|}
\hline \multirow{3}{*}{ Variáveis } & \multicolumn{5}{|c|}{ Pares canônicos } \\
\hline & 10 & $2^{\circ}$ & 30 & $4^{\circ}$ & $5^{\circ}$ \\
\hline & \multicolumn{5}{|c|}{ Grupo I (V - classes de uso da terra) } \\
\hline$x_{1}$ & 1,5444 & 0,8655 & 0,1866 & $-0,46$ & $-0,4492$ \\
\hline$x_{2}$ & 0,0039 & $-0,8839$ & 0,2881 & $-0,869$ & $-1,2622$ \\
\hline$x_{3}$ & 1,192 & 1,6607 & 0,5219 & $-0,4712$ & $-1,8323$ \\
\hline$x_{4}$ & 0,4061 & $-0,0648$ & 0,0891 & 0,724 & $-0,9428$ \\
\hline \multirow[t]{2}{*}{$x_{5}$} & 0,8144 & 1,8205 & 1,0796 & 0,2555 & 0,2043 \\
\hline & \multicolumn{5}{|c|}{ Grupo II (U - parâmetros de qualidade da água subterrânea) } \\
\hline$Y_{1}$ & $-0,0674$ & 0,2596 & 0,327 & 0,5377 & $-0,2162$ \\
\hline$Y_{2}$ & 0,3221 & $-0,1923$ & 0,1029 & 0,1037 & 0,535 \\
\hline$Y_{3}$ & 0,6661 & 0,2037 & 0,5284 & 0,1549 & 0,5406 \\
\hline$Y_{4}$ & $-0,7362$ & 0,3647 & $-0,3521$ & $-0,8108$ & 0,2012 \\
\hline$Y_{5}$ & $-0,3293$ & 0,6466 & 0,1974 & 0,1975 & $-1,1007$ \\
\hline$Y_{6}$ & 0,3085 & 0,4928 & $-0,0976$ & $-0,4004$ & 0,0646 \\
\hline$Y_{7}$ & $-0,1542$ & $-0,8632$ & $-0,1005$ & 0,2205 & 0,7256 \\
\hline$Y_{8}$ & 0,1829 & $-0,6375$ & 0,5293 & $-0,7503$ & 0,4696 \\
\hline$Y_{9}$ & 0,8874 & $-0,5054$ & $-0,3473$ & $-0,088$ & 0,6311 \\
\hline$Y_{10}$ & 0,5748 & $-1,3159$ & 0,1134 & 0,4124 & 0,9443 \\
\hline$Y_{11}$ & $-0,2649$ & $-0,1399$ & 0,132 & $-0,5614$ & 0,2684 \\
\hline $\mathrm{R}$ & 0,97655 & 0,92213 & 0,86925 & 0,68399 & 0,41166 \\
\hline$\Lambda$ & $0,74910^{-3}$ & 0,01617 & 0,10802 & 0,44197 & 0,83054 \\
\hline$\chi^{2}$ & 75,56235 & 43,30973 & 23,36699 & 8,57343 & 1,94968 \\
\hline $\mathrm{p}$ & $0,034^{*}$ & $0,3^{21} \mathrm{~ns}$ & $0,6651^{\text {ns }}$ & 0,9299 ns & $0,9625^{\mathrm{n}}$ \\
\hline
\end{tabular}

*significativo ao nível de $5 \%$ de probabilidade pelo teste do $\chi^{2}(p<0,05)$; nsnão significativo ao nível de $5 \%$ de probabilidade $(p>0,05)$.

R: correlação canônica; $\Lambda$ : valor de Lambda; $\chi^{2}$ : qui-quadrado calculado.

$\tilde{\beta}_{1}^{\prime}$ : primeira coluna da Tabela 5 do Grupo II, sendo $\tilde{X}^{\star}$ o vetor $\tilde{X}$ padronizado e $\tilde{Y}^{\star}$ o vetor $\tilde{Y}$ padronizado.

Desta forma, o módulo do primeiro par canônico é 0,9765, ou seja, $\left|\operatorname{Corr}\left(\mathrm{V}_{1}, \mathrm{U}_{1}\right)=0,9765\right|$, mostrando que existe tendência significativa entre os dois grupos. Portanto, há uma considerável relação (linear) entre as classes de uso da terra e os parâmetros de qualidade da água subterrânea. Assim, as variáveis canônicas do Grupo I, classes de uso da terra e do Grupo II, parâmetros de qualidade de água subterrânea, serão chamados daqui por diante de "índice de uso da terra" e "índice de qualidade da água", respectivamente.

Com base nesses resultados, ficou evidenciada a importância do estudo de correlações canônicas no entendimento das relações entre os grupos, pois as magnitudes das correlações simples algumas vezes não refletiram adequadamente a relação causa-efeito entre os grupos. É importante ressaltar que as correlações canônicas são análogas aos coeficientes de correlação simples. A diferença é que a correlação canônica mede a associação entre variáveis aleatórias e não entre as variáveis originais.

Os valores da Tabela 5 mostram uma tendência das classes de área agricultada e pastagem no aumento de alguns elementos $\left(\mathrm{NO}_{3}\right.$, $\mathrm{P}$ total e $\mathrm{K}^{+}$), mesmo que as concentrações desses elementos não sejam tão expressivas.

Alguns autores sugerem que as práticas de cultivo do solo podem provocar contaminação difusa, principalmente por nutrientes (FOSTER et al., 1991; MIRLEAN et al., 2005) e, às vezes, 
por agrotóxicos. No entanto, outros nutrientes essenciais para a planta, como $\mathrm{K}^{+}$e o $\mathrm{P}$ total, tendem a ficar retidos no solo ou podem lentamente ser lixiviados para a água subterrânea. Segundo Foster et al. (2001), os tipos de atividade agrícola responsáveis pelos casos mais graves de contaminação difusa da água subterrânea são aqueles relacionados com áreas extensas de monocultura. Os cultivos rotativos tradicionais, a pastagem extensiva e os sistemas agroecológicos normalmente apresentam uma menor probabilidade de contaminação do subsolo.

Os coeficientes da equação apresentados na Tabela 5 são os "pesos canônicos" e estes são similares aos "betas" de uma regressão múltipla. O uso dos pesos para analisar uma função canônica pode acarretar alguns problemas como instabilidade dos valores em função da amostra e dificuldades de interpretação dos valores em um ambiente com multicolinearidade. Para determinar a importância relativa das variáveis para cada composto canônico, é melhor utilizar as cargas canônicas, descrita nas Tabelas 6 e 7 .
Na Tabela 6, estão apresentados os resultados das correlações entre a variável canônica $V_{1}$ (“índice uso da terra”) e as componentes padronizadas do vetor $\tilde{X}$, também chamados de "cargas canônicas entre $\mathrm{V}_{1}$ e Xi, $\mathrm{i}=1,2,3,4,5$ ”. Na Tabela 7 , encontra-se o resultado das correlações entre a variável canônica $U_{1}$ ("índice de qualidade da água") e os componentes padronizadas do vetor $\tilde{Y}$, também chamados de "cargas canônicas entre $\mathrm{U}_{1}$ e $\mathrm{Yi}, \mathrm{i}=1,2,3,4, \ldots, 11$ ".

Com base na Tabela 6 , a variável $\mathrm{X}_{1}$, área agricultada, é a que mais contribui, dentre as classes descritas, para a alteração da qualidade da água subterrânea na área estudada. As demais classes de uso da terra afetaram a qualidade da água subterrânea de forma menos evidenciada. Com base na Tabela 7 , a variável $\mathrm{Y}_{9}$, concentração de $\mathrm{NO}_{3}$, é o parâmetro de qualidade de água que foi mais influenciado pelas classes de uso da terra. Esse resultado indica que o aumento na porcentagem de área agricultada aumenta as concentrações de $\mathrm{NO}_{3}^{-}$na água subterrânea. Já os demais parâmetros de qualidade da água parecem não ser influenciados de forma significativa pelas diferentes classes de uso da terra.

Tabela 6 - Resultado do vetor de correlação entre a variável canônica $\mathrm{V}_{1}$ (índice uso da terra) e as componentes padronizadas do vetor $\tilde{X}$.

\begin{tabular}{l|c|c} 
& Vetor $\tilde{X}$ & Correlação entre $V_{1}$ e $X_{i}$ \\
$X_{1}$ & Área agricultada & 0,8826 (forte) \\
\hline$X_{2}$ & Área edificada & 0,0558 (fraca) \\
\hline$X_{3}$ & Pastagem & -0,4302(moderada) \\
\hline$X_{4}$ & Solo exposto & 0,3435 (moderada) \\
\hline$X_{5}$ & Vegetação intermediaria & 0,0122 (muito fraca) \\
\hline
\end{tabular}

Nota: foi adotada a seguinte tabela de classificação do grau de correlação (valores em módulo) - abaixo de 0,05: muito fraca; 0,05 a 0,20: fraca; de 0,20 a O,30: fraca a moderada; de 0,30 a 0,70: moderada; de 0,70 a 0,80: moderada a forte; de 0,80 a 0,95: forte; acima de 0,95: muito forte (não há na literatura uma classificação ótima dos limites, esta é apenas uma referência para dar sequência ao trabalho de interpretação das variáveis canônicas).

Tabela 7 - Resultado do vetor de correlação entre a variável canônica $U_{1}$ (índice de qualidade da água) e as componentes padronizadas do vetor $\tilde{Y}$.

\begin{tabular}{l|c|c} 
& Vetor $\tilde{Y}$ & Correlação entre $U_{1}$ e Yi \\
$Y_{1}$ & $\mathrm{STD}$ & $-0,1064$ (fraca) \\
\hline$Y_{2}$ & $\mathrm{pH}$ & $-0,0295$ (muito fraca) \\
\hline$Y_{3}$ & $\mathrm{~K}^{+}$ & 0,0419 (muito fraca) \\
\hline$Y_{4}$ & $\mathrm{Na}^{+}$ & $-0,0450$ (muito fraca) \\
\hline$Y_{5}$ & $\mathrm{Fe}^{+3}$ & 0,0187 (muito fraca) \\
\hline$Y_{6}$ & $\mathrm{Ca}^{+2}$ & 0,1621 (fraca) \\
\hline$Y_{7}$ & $\mathrm{Mg}^{+2}$ & $-0,5225$ (moderada) \\
\hline$Y_{8}$ & $\mathrm{NO}_{2}$ & 0,0139 (muito fraca) \\
\hline$Y_{9}$ & $\mathrm{NO}_{3}$ & 0,6098 (moderada forte) \\
\hline$Y_{10}$ & $\mathrm{Ptotal}_{11}$ & 0,0217 (muito fraca) \\
\hline$Y_{11}$ & Coliformes termotolerantes & 0,1419 (fraca)
\end{tabular}

Nota: foi adotada a seguinte tabela de classificação do grau de correlação (valores em módulo) - abaixo de 0,05: muito fraca; 0,05 a 0,20: fraca; de 0,20 a 0,30: fraca a moderada; de 0,30 a 0,60: moderada; de 0,60 a 0,80: moderada a forte; de 0,80 a 0,95: forte; acima de 0,95: muito forte (não há na literatura uma classificação ótima dos limites, esta é apenas uma referência para dar sequência ao trabalho de interpretação das variáveis canônicas). 
A contaminação por nitrogênio das áreas agricultadas e de pastagem possivelmente tem como fonte a utilização de dejetos animais nos cultivos próximos aos poços e/ou devido à presença destes circulando na área de entorno. A decomposição da matéria orgânica do solo (PERCEBON \& BITTENCOURT, 2009), especificamente a biodegradação de proteínas, libera amônia, que é transformada em nitrito e depois em nitrato, dentro da ciclagem do nitrogênio. Da mesma forma, Davies e De Wiest (1991) salientam que águas superficiais contaminadas com $\mathrm{NO}_{3}$ - que alimentam aquíferos podem também contaminá-los.

\section{CONCLUSÃO}

A análise dos resultados permite tecer as seguintes conclusões.

$\mathrm{O} \mathrm{Na}^{+}$e o $\mathrm{Ca}^{+2}$ foram os cátions de maior influência na concentração dos STD das águas estudadas, apresentando também influência significativa nos valores do $\mathrm{pH}$. A origem do $\mathrm{P}$ total possivelmente provém de atividades antrópicas, uma vez que as rochas cristalinas (granitos e gnaisses) que compõem o Sistema Aquífero Cristalino não costumam fornecer esse elemento para a água subterrânea.

$\mathrm{O}$ primeiro par das variáveis canônicas $\left(\mathrm{V}_{1}, \mathrm{U}_{1}\right)$ foi significativo a $5 \%$ de probabilidade, mostrando que existe uma considerável relação (linear) entre as classes de uso da terra e os parâmetros de qualidade da água subterrânea na área estudada. A correlação dos dois grupos mostra que há influência das classes de área agricultada nas variações da qualidade da água subterrânea, sobretudo no aumento da concentração de $\mathrm{NO}_{3}$. A variável canônica $\mathrm{U}_{1}$ ("índice de qualidade da água") restringe-se às condições consideradas nesta pesquisa, ou seja, um estudo de caso na zona rural, com classes de uso do solo típicas desse ambiente.

Para trabalhos em escala regional, recomenda-se que as áreas de contribuição dos poços sejam delimitadas com base na hidrodinâmica subterrânea, isto é, no caso de aquíferos livres, deve-se considerar a inclinação das vertentes, as possíveis áreas de recarga e a condutividade hidráulica do meio.

\section{REFERÊNCIAS}

AMERICAN PUBLIC HEALTH ASSOCIATION; AMERICAN WATER WORKS ASSOCIATION; WATER ENVIRONMENT - APHA; AWWA; WEF (2005) Standard methods for the examination of water and wastewater. $21^{15 t}$ ed. Washington DC: APHA; AWWA; WEF.

AN, Y.J.; KAMPBELL, D.H.; JEONG, S.W.; JEWELL, K.P.; MASONER, J.R. (2005) Impact of geochemical stressors on shallow groundwater quality. Journal of Hydrology, v. 348, p. 257-266

ASSOCIAÇÃO BRASILEIRA DE NORMAS TÉCNICAS - ABNT (1989) NBR 10664: Águas - Determinação de resíduos (sólidos) - Método gravimétrico. Rio de Janeiro: ABNT.

ASSOCIAÇÃO BRASILEIRA DE NORMAS TÉCNICAS - ABNT (1987) NBR 9898: Preservação e técnicas de amostragem de efluentes líquidos e corpos receptores. Rio de Janeiro: ABNT.

BHATTACHARYA, P.; AHMED, K.M.; HASAN, M.A.; BROMS, S.; FOGELSTROM, J.; JACKS, G.; SRACEK, O.; BROMSSEN, M.; ROUTH J. (2006) Mobility of arsenic in groundwater in a part of Brahmanbaria district, NE Bangladesh. In: NAIDU, R.; SMITH, E.; OWENS, G.; BHATTACHARYA, P.; NADEBAUM, P. (eds.) Managing arsenic in the environment: from soil to human health. Melbourne: CSIRO, p. 95-115.

BRUCE, B.W. \& MCMAHON, P.B. (1996) Shallow ground-water quality beneath a major urban center: Denver, Colorado, USA. Journal of Hydrology, v. 186, p. 129-151.

CAIN, D.; HELSEL, D.R.; RAGONE, S.E. (1989) Preliminary evaluations of regional ground-water quality in relation to land use. Ground Water, v. 27, p. 230-244.
CALIJURI, M.L.; COUTO, E.A.; SANTIAGO, A.F.; CAMARGO, R.A.; SILVA M.D.F.M. (2012) Evaluation of the influence of natural and anthropogenic processes on water quality in karstic region. Water, Air, \& Soil Pollution, v. 223 , n. 5, p. 2157-2168

CHAE, G.T.; KIM, K.; YUN, S.T.; KIM, K.; KIM, S.O.; CHOI, B.Y. KIM, H.S.; RHEE, C.W. (2004) Hydrogeochemistry of alluvial groundwaters in an agricultural area: an implication for groundwater contamination susceptibility. Chemosphere, v. 3, p. $369-378$

CHILTON, P.J. \& FOSTER, S.S.D. (1995) Hydrological characterization and water-supply potential of basement aquifers in tropical Africa. Hydrogeology Journal, v. 3, n. 1, p. 36-49.

CUSTODIO, E. \& LLAMAS, M. (1996) Hidrología subterránea. 2. ed. Barcelona: Omega. 2v.

DAS, M.; KUMAR, A.; MOHAPATRA, M.; MUDULI, S. (2010) Evaluation of drinking quality of groundwater through multivariate techniques in urban area. Environmental Monitoring and Assessment, v. 166, n. 1-4 p. 149-157.

DAVIES, S.N. \& DE WIEST, R.J.M. (1991) Hydrogeology. Florida: Krieger Publishing

ESRI (2011) ArcGIS - ArcMap 10 Help On Line. Redlands, CA: ESRI.

FOSTER, S.S.D.; CHILTON, P.J.; STUART, M.E. (1991) Mechanisms of groundwater pollution by pesticides. Water and Environment Journal v. 5, n. 2, p. 186-193. 
FOSTER, S.S.D.; HIRATA, R.C.A.; GOMES, D.; D’ELIA, M.; PARIS, M. (2OO1) Groundwater quality protection: a guide for water service companies, municipal authorities and environment agencies. Washington DC: Banco Mundial.

HAIR, J.F. (1998) Multivariate data analysis. $5^{\text {th }}$ ed. New Jersey: Prentice Hall.

HIRATA, R.; REBOUÇAS, A. (1999) La protección de los recursos hídricos subterráneos: una visión integrada, basada en perímetros de protección de pozos y vulnerabilidad de aquíferos. Boletín Geológico y Minero, v. 110, n. 4, p. 423-436.

HUNTINGTON, T.G. (2006) Evidence for intensification of the global water cycle: review and synthesis. Journal of Hydrology, v. 15, p. 1-4

INSTITUTO BRASILEIRO DE GEOGRAFIA E ESTATÍSTICA - IBGE (2O10) Produção da Pecuária Municipal 2009. Rio de Janeiro: IBGE.

JEONG, C.H. (2001) Effect of land use and urbanization on hydrochemistry and contamination of groundwater from Taejon area, Korea. Journal of Hydrology, v. 253, p. 194-210.

LACHASSAGNE, P.; WYNS, R.; BERARD, P.; BRUEL, T.; CHÉRY, L.; COUTAND, T.; DESPRATS, J-F.; LE STRAT, P. (2001) Exploitation of highyields in hard-rock aquifers: downscaling methodology combining GIS and multicriteria analysis to delineate field prospecting zones. Ground Water, v. 39, n. 4, p. 568-581.

LI, R. \& MERCHANT, J.W. (2013) Modeling vulnerability of groundwater to pollution under future scenarios of climate change and biofuelsrelated land use change: a case study in North Dakota, USA. Science of the Total Environment, v. 447, p. 32-45.

LOBO-FERREIRA, J.P.; DIAMANTINO, C.; LEITÃO, T.E.; OLIVEIRA, M.M.; MOINANTE, M.J.; ARTUSO, E.; ZAKHAROVA, T. (2003) Projecto FCT Valorização e Proteç̧ão da Zona Costeira Portuguesa: avaliação e estudo da vulnerabilidade de sistemas aquíferos costeiros (Componente 11). Relatório 265/O3-NAS. Lisboa: LNEC.

MCARTHUR, J.M.; BANERJEE, D.M.; HUDSON-EDWARDS, K.A.; MISHRA, R.; PUROHIT, R.; RAVENSCROFT, P.; CRONIN, A.; HOWARTH, R.J.; CHATTERJEE, A.; TALUKDER, T.; LOWRY, D.; HOUGHTON, S.; CHADHA, D.K. (2004) Natural organic matter in sedimentary basins and its relation to arsenic in anoxic ground water: the example of West Bengal and its worldwide implications. Applied Geochemistry, v. 19, p. 1255-1293.

MCARTHUR, J.M.; RAVENCROFT, P;; SAfiULLAH S.; THIRLWALL, M.F. (2001) Arsenic in groundwater: testing pollution mechanism for sedimentary aquifers in Bangladesh. Water Resources Research, v. 37, p. 109-117.
MIRLEAN, N.; MACHADO, M.I.; OSINALDI, G.M.; DEMOLINER, A.; BAISCH, P. (2005) O impacto industrial na composição química das águas subterrâneas com enfoque de consumo humano (Rio Grande, RS). Química Nova, v. 3, p. 788-791.

NAIR, A.; ABDALLA, G.; MEHMED, I.; PREMKUMAR, K. (2005) Physicochemical parameters and correlation coefficient of ground waters of north-east Libiya. Pollution Research, v. 24, p. 1-6.

NEVES, M.A.; MORALES, N. (2006) Well productivity controlling factors in crystalline terrains of southeastern Brazil. Hydrogeology Journal, v. 15, p. 471-482.

NOLAN, B.T; HITT, K.J.; RUDDY, B.C. (2002) Probability of nitrate contamination of recently recharged groundwaters in the conterminous United States. Environmental Science \& Technology, v. 36, p. 2138-2145

OKI, T. \& KANAE, S. (2006) Global hydrological cycles and world water resources. Science, v. 313, p. 1068-1072.

PERCEBON, L.M. \& BITTENCOURT, A.V.L. (2009) Considerações sobre as características de qualidade das águas subterrâneas de Blumenau SC em relação à Resolução CONAMA 396. Águas Subterrâneas, v. 23, p. 69-84.

SHRESTHAS. \& KAZAMA F. (2007) Assessment of surface water quality using multivariate statistical techniques: A case study of the Fuji river basin, Japan. Environmental Modelling \& Software, v. 22, p. 464-475

SQUILLACE, P.J.; SCOTT, J.C.; MORAN, M.J.; NOLAN, B.T.; KOLPIN, D.W (2002) VOCs, pesticides, nitrate, and their mixtures in groundwater used for drinking water in the United States. Environmental Science \& Technology, v. 36, n. 9, p.1923-1930.

STROHSCHÖN, R.; WIETHOFF, K.; BAIER, K.; LU, L.; BERCHT, A.L.; WEHRHAHN, R.; AZZAM, R. (2013) Land use and water quality in Guangzhou, China: a survey of ecological and social vulnerability in four urban units of the rapidly developing megacity. International Journal of Environmental Research, v. 7, n. 2, p. 343-358.

TIMM, N.H. (2002) Applied multivariate analysis. New York: Springer.

TROJAN, M.D.; MALONEY, J.S.; STOCKINGER, J.M.; EID, E.P.; LAHTINEN, M.J. (2003) Effects of land use on ground water quality in the Anoka Sand Plain Aquifer of Minnesota. Ground Water, v. 41, n. 4, p. 482-492.

WHITE, P.; RUBLE, C.L.; LANE, M.E. (2O13) The effect of changes in land use on nitrate concentration in water supply wells in southern Chester County, Pennsylvania. Environmental Monitoring and Assessment, v. 185, n. 1, p. 643-651. 
Anexo 1 - Fotointerpretação do uso da terra com suas respectivas áreas (\%).
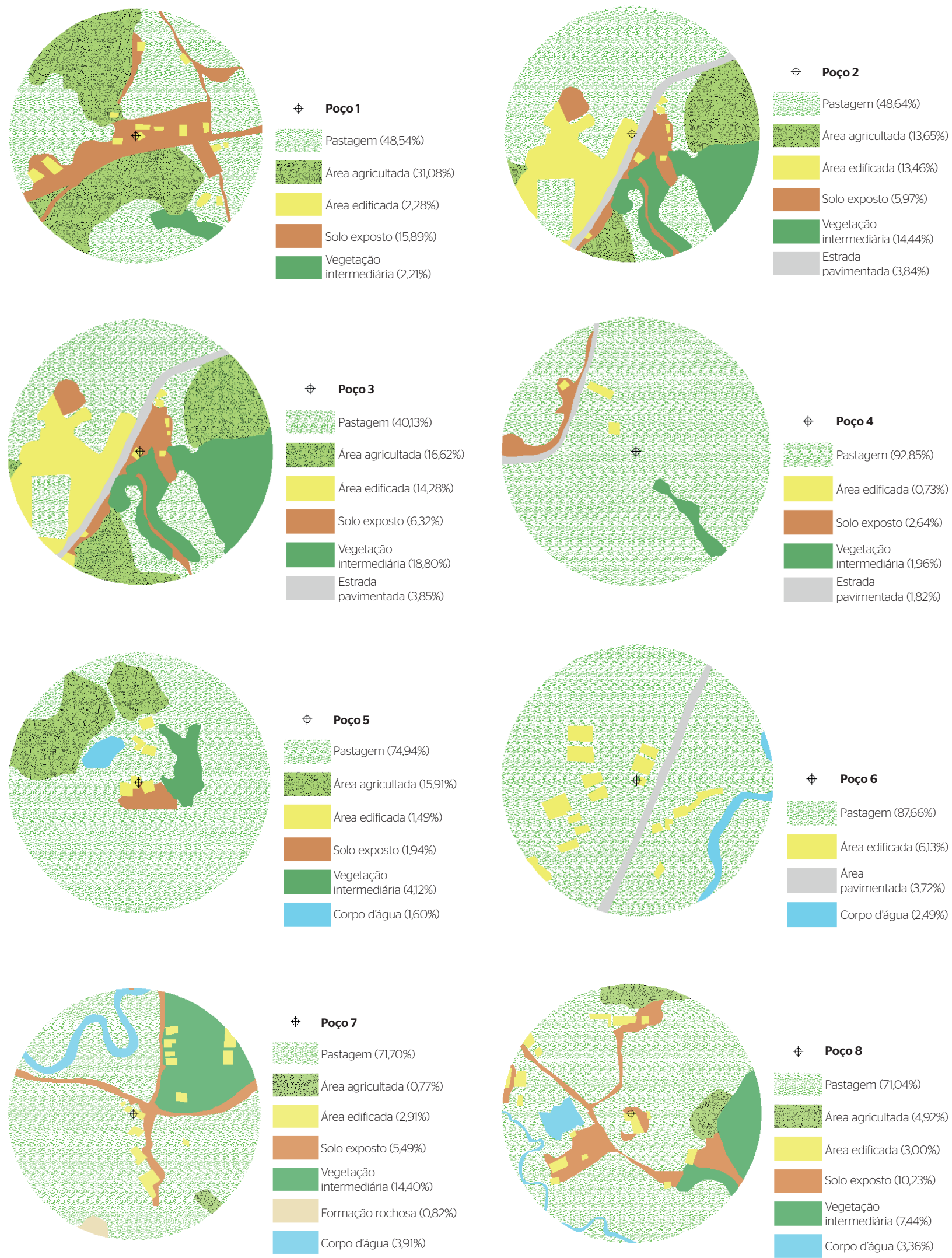


\section{Anexo 1 - Continuação.}
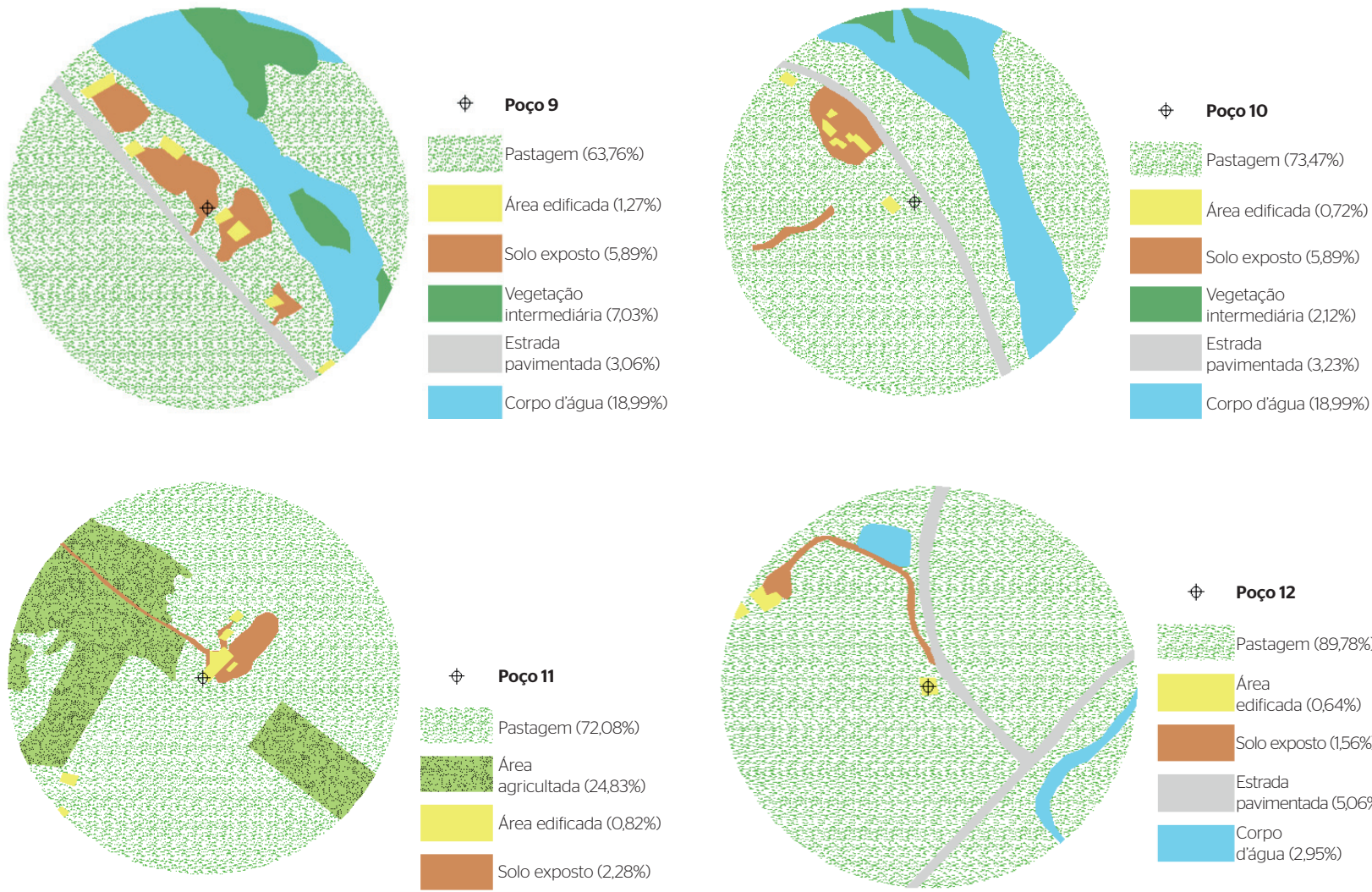

P. Pastagem (89,78\%)
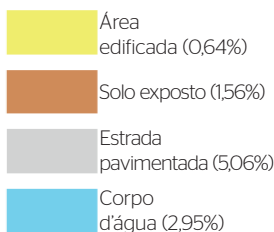
dágua (2,95\%)

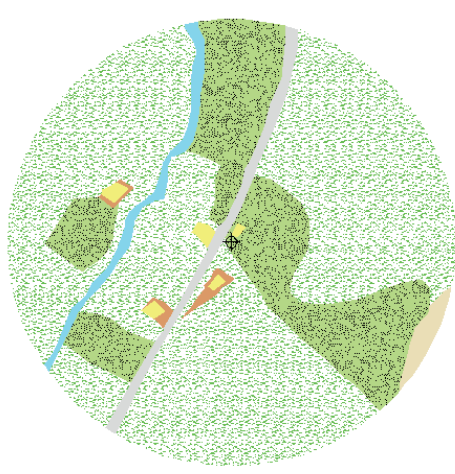

\section{申 Poço 13}
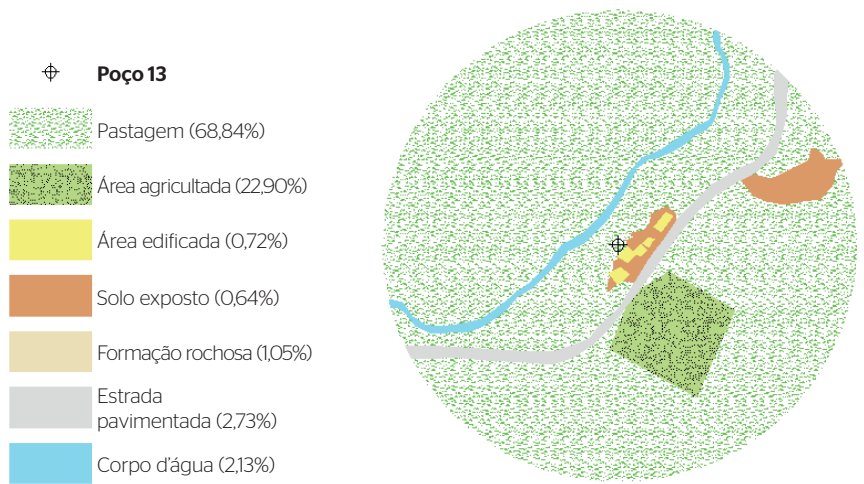

申 Poço 14
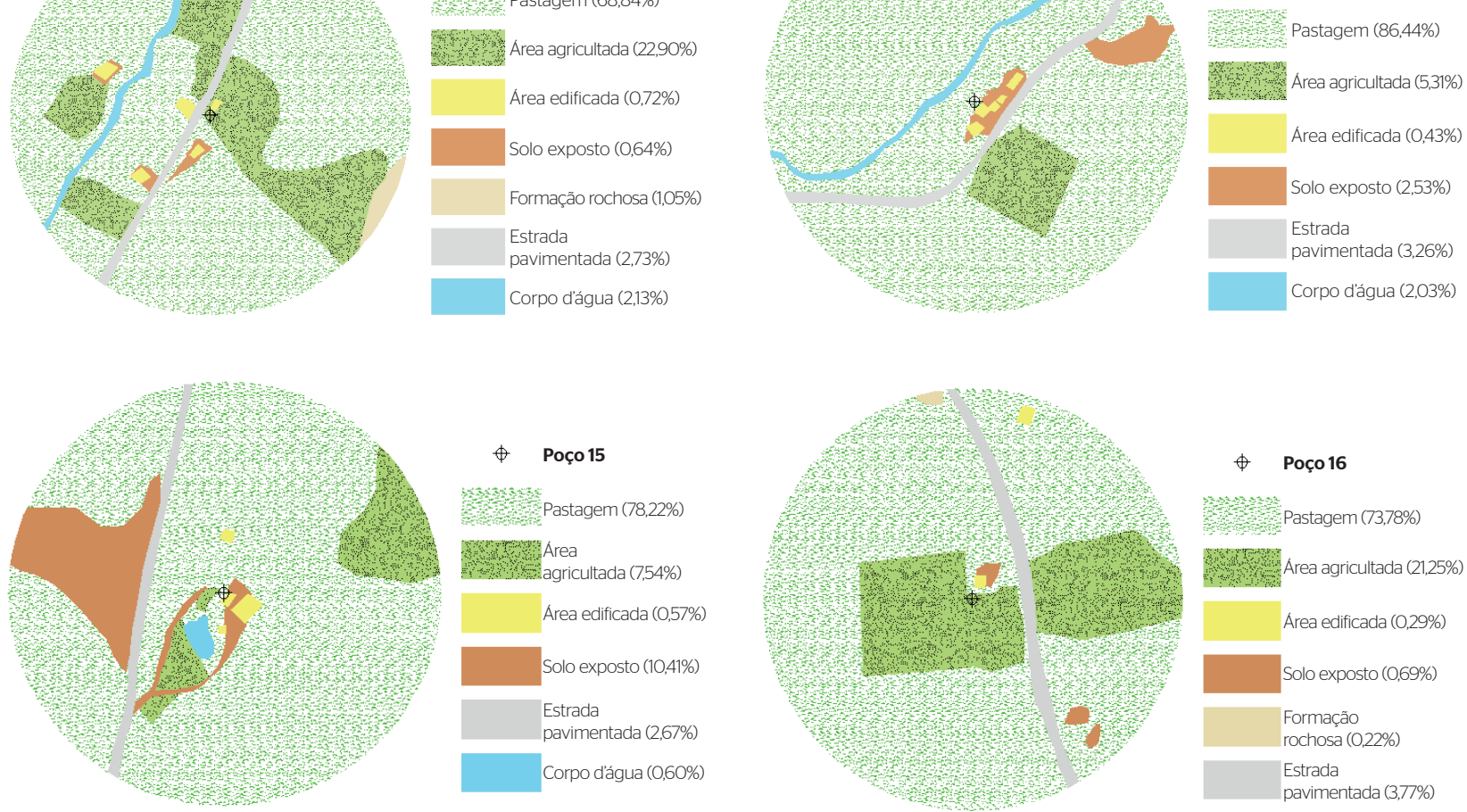

\section{Đ Poço 15}

Y) Pastagem $(78,22 \%)$

MrTS Area

1.7. Ele agricultada $(7,54 \%)$

Area edificada $(0,57 \%)$

Solo exposto $(10,41 \%)$

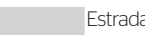

pavimentada $(2,67 \%)$

Corpo dágua (0,60\%)

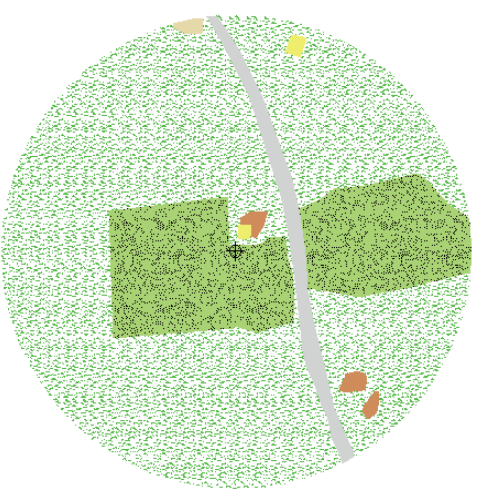

\section{๑) Poço 16}

2. Pastagem $(73,78 \%)$

N1. Area agricultada $(21,25 \%)$

Area edificada $(0,29 \%)$

Solo exposto $(0,69 \%)$

Formação rochosa $(0,22 \%)$

Estrada pavimentada $(3,77 \%)$ 
Anexo 1 - Continuação.

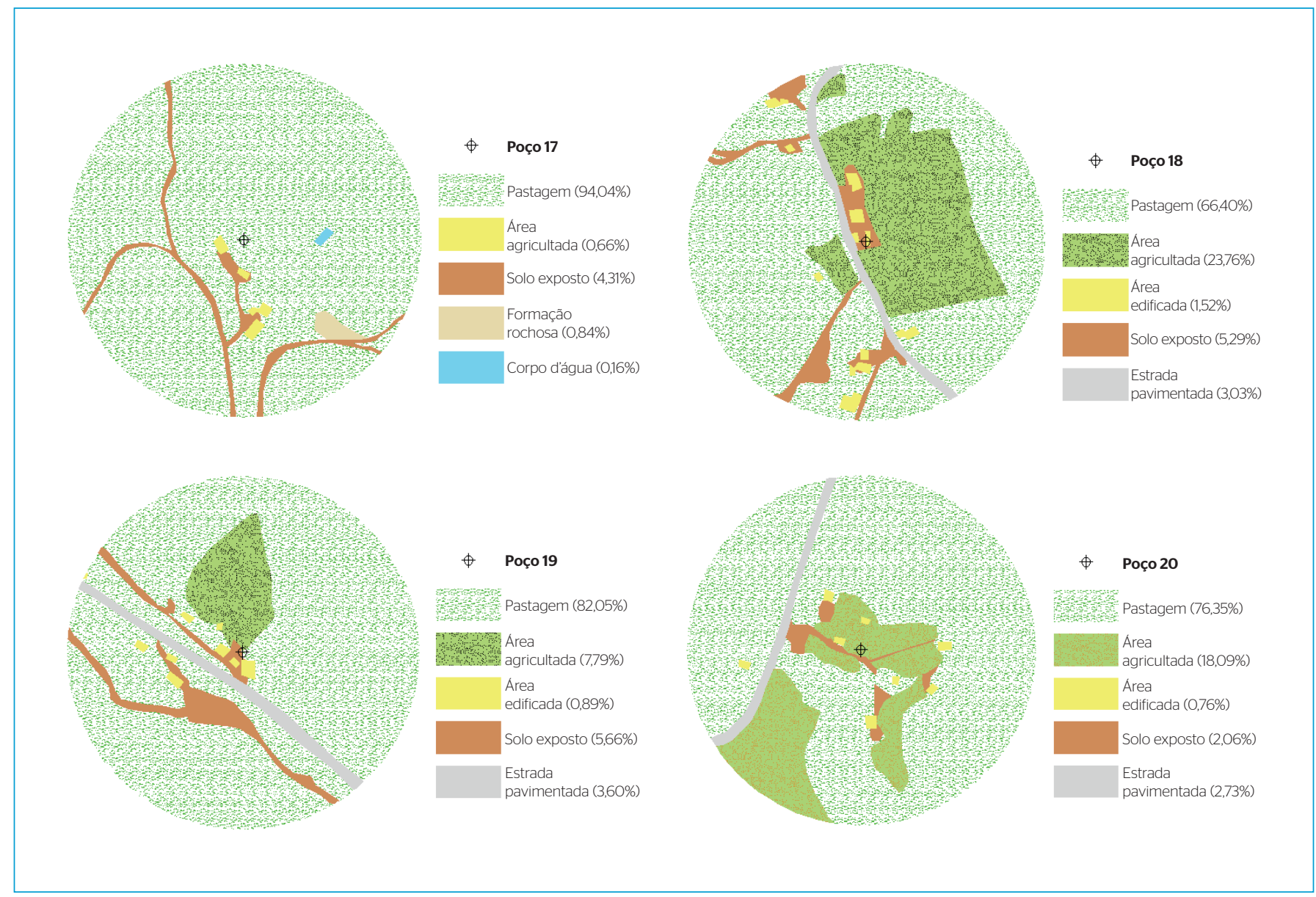

